\title{
Procedure Agents Link Group Identifier
}

National Cancer Institute

\section{Source}

National Cancer Institute. Procedure Agents Link Group Identifier. NCI Thesaurus. Code C162030.

A sequence of characters used to link multiple procedure agents records to a single finding. 